\title{
Study on Improvement and Development of College English Autonomous Learning Field within Ubiquitous Learning Community
}

\author{
Huan-Huan Ren \\ Teaching and Research Institute of Foreign Languages \\ Bohai University \\ Jinzhou, China \\ E-mail: renhuanhuan2014@163.com
}

\author{
Chi Ma \\ Jinzhou Institute of Forestry Research \\ Jinzhou Forestry Bureau \\ Jinzhou, China \\ E-mail: machi2014@tom.com
}

\begin{abstract}
It's about time when everyone is involved in acquiring new knowledge and skills with the aid of ubiquitous and wireless technologies. This research is addressing a number of research topics pertinent to ubiquitous learning in view of Bourdieu's theory of practice. With regard to Bourdieu's theory of practice, preliminary analysis on college English autonomous learning field in China are conducted by researchers from aspects of background drives, general rationales and concrete solutions in ubiquitous learning space. Furthermore, practical suggestions for improvement and development of college English autonomous learning field within ubiquitous learning community are specified and argued, taking account of physical space, informational space, social space and power space in college English autonomous learning field, so that far-reaching benefits within ubiquitous learning community are anticipated for future educational approaches in Chinese college English language learning field.
\end{abstract}

Keywords-improvement; development; college English; autonomous learning field; ubiquitous learning community

\section{INTRODUCTION}

The world is undergoing transformations from deskbased learning to ubiquitous learning due to rapid development of enabling technologies. Education enters into a new era, and the environment for learning is open to all possibilities and potentials. U-learning community, a new learning genre, is in support of college English autonomous learning mode, and is expected to have much more to offer future language learning. Drawing on Bourdieu's theory of practice, this research seeks to explore the improvement and development of college English autonomous learning field within u-learning community. It's argued that the use of Bourdieu's theory of practice as a research framework could allow researchers to fully explore interactive practice of learning elements within the learning field. And theoretical analysis and practical suggestions for improvement and development of college English autonomous learning field are discussed in present paper, so that far-reaching benefits are anticipated for future educational approaches in English language learning field within u-learning community.

\section{LITERATURE REVIEWS ON BOURDIEU'S THEORY}

\section{A. Bourdieu's Theory of Practice}

Pierre Bourdieu is a distinguished French sociologist who is considered by researchers as one of the most important sociologists of the second half of the 20th century. He had become a necessary reference point in various areas as he wrote over thirty studies of a wide scope and different value, from substantial scientific significance to the papers speaking about his explicit public engagement. Pierre Bourdieu's social theory is often named as a theory of practice. As the name indicates, theory of practice centers on practices, the embodied sets of activities that humans perform with varying degrees of regularity, competence and flair, rather than structures, systems, individuals or interactions [1]. Theory of practice is dealing with how social beings, with their diverse motives and their diverse intentions, make and transform the world in which they live. It is dialectic between social structure and human agency working back and forth in a dynamic relationship [2]. This theory is simultaneously a critique of the methods and postures of social science and a general account of how human action should be understood. All in all, Bourdieu's theory of practice is one of his key contributions to social sciences and humanities.

\section{B. Views on Habitat and Field}

Bourdieu's work uses the concepts of field and habitus to explain interactions within the social world. For Bourdieu, the social world has gradually divided into what he calls fields. Fields are specialist domains of practice with their own 'logic' that are constituted by a unique combination of species of capital [3]. Each field is a structured social space with its own rules, schemes of domination, legitimate opinions. Bourdieu uses the concept of field instead of analyzing societies solely in terms of classes. An apt metaphor for a field is that of a game. Only players with sufficient 'know-how' and belief in the game will be willing to invest time and effort playing it [4]. A second key concept in the Bourdieu's theoretical lexicon is habitus. Habitus is collective system of dispositions (i.e. lasting, acquired schemes of perception, thought and action) that individuals or groups have. It captures the permanent internalization of the social order in the human body [5]. A closely related notion to Bourdieu's habitus is Michel Foucault's concept of 'discipline', which features the violence through which modern regimes are used as a form of social control [6]. However, this concept of habitus has been praised for overcoming the mind-body and objectivity vs. subjectivity 
dichotomies that have been so deeply engrained in western philosophy [7].

\section{Learning Field within U-learning Community}

Fields can fall into different categories, such as art, photography, sociology, etc, and learning field is a specialist domain of practice in which learners and their learning positions are located in. The position of each particular learner in the field is a result of interaction between the specific rules of the field, learner's habitus and agent's capital. The differentiation of learning activities lead to the constitution of various, relatively autonomous spaces in which competition centers around particular species of capital. These fields are treated on a hierarchical basis and the dynamics of fields arise out of the struggle of learners trying to occupy the dominant positions within the field. According to Bourdieu, the learner' successful strategies may appear to the casual observer rational and conscious, but in reality, they are only possible when there is a good fit between the habitus and the field [8]. In a word, Bourdieu's sociology has much to offer the study of technology, through providing a useful conceptual lens for describing how students use and engage with technology, as well as shape their response to new environment.

III. PRELIMINARY ANALYSIS OF COLLEGE ENGLISH AUTONOMOUS LEARNING FIELD WITHIN U-LEARNING COMMUNITY

Various interaction occurs in college English autonomous learning field, and analysis of the field can be conducted through answering three questions, namely, why to develop college English autonomous learning field, how to develop college English autonomous learning field and from what aspects to develop college English autonomous learning field, as shown in Fig.1. Specifically, this section tries to argue for background reasons for field development, general rationales from multi-disciplines, and concrete solutions by sub-space division.

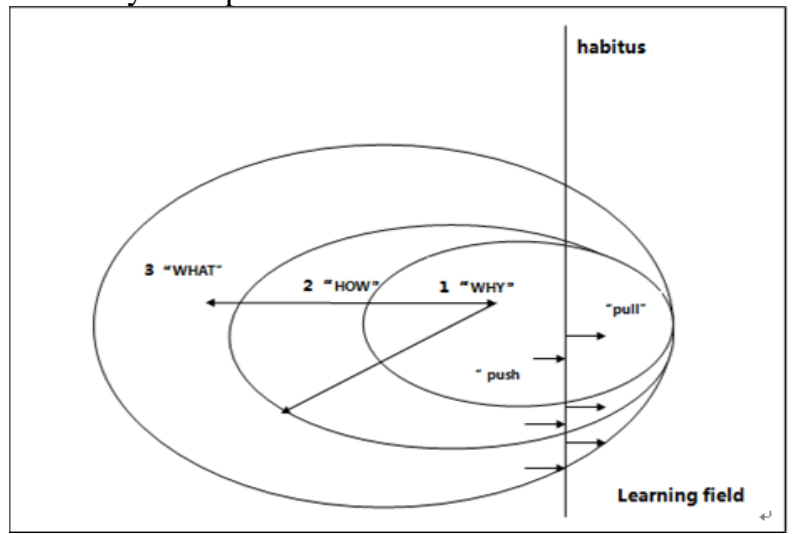

Figure 1. Preliminary analysis of college English autonomous learning field.

\section{A. Background Reasons for Field Development}

The drive for the development of college English autonomous learning field within u-learning community is twofold. On one hand, learners are motivated to grow and make a difference in learning field. College English students entail expressing and reproducing their dispositions in institutional arenas, and thereby complete for the distribution of different kinds of capital. This is the time when learners are involved into a new paradigm of learning. The focus of the learner is on practices, especially the habitus and the ways that various capitals are drawn on and exerted in learning fields. On the other, learning field is open to possibilities and potentials despite the fact that there are specific laws of each field. The network, structure or set of relationships in college English autonomous learning field within u-learning community are subject to evolution. Positions of learners in the learning field are interrelated and vertically differentiated in this technology-assisted learning field. With the advent of enabling technologies, learning context and environment are key influences on habitus of learners. In sum, whilst u-learning community is set to enter in the field of education, the construction and development of college English autonomous learning field is evitable.

\section{B. General Rationales from Multi-disciplines}

Theory of practice is no doubt one dominant principle whist analyzing college English autonomous learning filed within u-learning community. It offers conceptual framework and fresh lens to address the problems occurring in college English autonomous learning filed. Besides it, other principles or philosophies especially in educational domain should also find their way and be adopted as key parts of tool kit of present study. The primary concern is constructivism, a learning theory found in psychology which explains how people might acquire knowledge and learn. People construct their own understanding and knowledge of the world, through experiencing things and reflecting on those experiences. When they continuously reflect on their experiences, students find their ideas gaining in complexity and power, and they develop increasingly strong abilities to integrate new information [9]. Another theory that deserves more attention is the theory of learner autonomy, according to which learners should possess the ability to take charge of their own learning and be active organisms seeking meaning within u-learning community. Learner autonomy can be achieved when certain conditions are obtained, especially, learners' attitudes towards autonomy, learners' motivation and their English language knowledge. In brief, combination and observation of multidisciplinary ideas can provide orientation for the college English autonomous learning filed.

\section{Concrete Solutions by Sub-space Division}

Sub-space divisions occur in college English autonomous learning filed, and each space is conducive to the development of this learning field especially within ulearning community. Four sub-spaces (i.e. physical space, informational space, social space and power space) are considered whist seeking concrete solutions for the development of college English autonomous learning field. Physical space stresses on the physical settings where English language learners undergo self-learning or assistedlearning for better development; Informational space 
concerns with how the information is delivered to English language learners, especially taking into consideration the efficiency and validity of information; Social space involves the interpersonal relationship with which English learners go on with their language learning, including all member (e.g. teacher, peer, etc.) within u-learning community; Power space refers to the distribution of power in college English autonomous learning field, with respect to fairness and equality of education in the learning field. All in all, the picture of learning field becomes clearer when looking at each respective sub-space in the learning field. Only each separate space is open to challenges and potentials, can the overall development of college English autonomous learning field be activated and achieved.

\section{IMPROVEMENT AND DEVELOPMENT OF COLLEGE ENGLISH AUTONOMOUS LEARNING FIELD WITHIN U-LEARNING COMMUNITY}

\section{A. Physical Space in College English Autonomous Learning Field}

As ubiquitous technologies break the barriers for education, physical space in college English autonomous learning field can be widely extended and expanded within u-learning community. On one hand, ubiquitous learning is not confined to physical classroom, nor fixed to a location or position. In the old times, physical devices are wired, and computation and communication learning is confined to the single desk. However, with the advances in wireless and mobile technologies (e.g. Wi-Fi, Bluetooth and GPS, etc.), ubiquitous learning overcomes the limitations of traditional learning, and education can continue outside the classroom. English language learners can learn at any time and at any place without thinking much about what time it is and where they are. In this case, 24/7 access to the learning environment and courses is enabled within u-learning community. Thus the existing physical space in college English autonomous learning field is improved. On the other, ubiquitous learning provides convenience for those who cannot reach out for the traditional learning. For example, for those with disabilities or those living in rural or remote communities, learning is not unattainable and far away any more, but rather, accessible and possible. No travel time or accommodation costs. They can get access to English language learning opportunities and be trained in shorter times within $\mathrm{u}-$ learning community. Enabling technologies make learning more beneficial and easier. Hence, language learners widen their access to education and obtain a greater and more advanced learning experience, so that the existing physical space in college English autonomous learning field is ultimately developed within u-learning community.

\section{B. Informational Space in College English Autonomous Learning Field}

As Albert Einstein said, "Learning is experience, everything else is just information". We are living in an era featuring information exploration or information overload, and the information space we are learning is more complex and various than before. It's a key issue to figure out information with high quality and make it at learners' disposal. Through use of smart and enabling technologies, informational space in college English autonomous learning field is optimized and customized within u-learning community. Firstly, English language learners are provided with rich, authentic and up-to-date language materials, which seek to make learning closer to the native language learning. Information required by learners can be delivered and transferred at any time and in real-time. Secondly, information delivered to English language learners within $\mathrm{u}$ learning community are personalized and context-aware, and learners can just get the right information at the right time. As the personal profile of students are recorded by learning systems including information about the learner's previous learning history, cognitive capabilities and other attributes, ulearning community can get deeper sight of individual learners. Meanwhile the system can contextualize the learning process through monitoring the student's actions and tailoring the information delivered to learners. Lastly, English learners acquire considerable amount information from their surroundings, often without even realizing it. As computers are seamlessly embedded in everyday objects, the learning process is so natural and non-obtrusive that the computer vanishes in learning environment, which deeply improves the quality of the educational procedures and optimizes informational space in college English autonomous learning field.

\section{Social Space in College English Autonomous Learning Field}

Ubiquitous learning is never a lonely and isolated independent learning, but rather entails social interaction in support of college English autonomous learning. Social space in college English autonomous learning field is enriched and diversified within u-learning communication. On one hand, u-learning is a very social experience and involves a lot of interactions and dialogues. Original electronic learning systems are set to provide a similar experience to that of a teacher transferring knowledge to the pupil, while u-learning aims to offer rich communication framework for multi-pupil learning experiences. With the aid of state-of-the-art systems, social networking issues are considered and integrated in the infrastructure of u-learning community, so that English language learners can continuously interact with hundreds, thousands, or millions of people from all walls of life and in every corner of the world through wirelessly networked computers. On the other, learners can experience a richer source of interaction as the approach of conversation and collaboration within u-learning are flexible and dynamic. More learning models and various activities are set to be undertaken by English language learners to deepen two-way collaboration or multiple communications. The location-awareness service is used to help learners form face-to-face and real-time learning groups, and each learner is part of a many-to-one relationship so as to allow students to collaboratively learn within the ubiquitous space. Not only do they learn from each other, or even teach one another, but they are also encouraged to catch up with each other as best. Through intensive dialogues and 
collaborative learning, learners become savvy about directing their learning process and pursuing desired learning outcomes.

\section{Power Space in College English Autonomous Learning Field}

In traditional classroom learning, the relationship between instructors and learners are not put into equal position, and their relationship is caught with chain of power. Teachers play a dominating part in students' learning instead of playing a guiding part. With the aid of information and communication technologies, power space in college English autonomous learning field within u-learning community is becoming flattening and constraint-free. Firstly, English language students dominate their study and take charge of their own learning content and learning process. All members within u-learning community are learners regardless of their actual positions in reality life. Students are equal in u-learning and they are neither top-level management nor low-level stuff. Learners enjoy a peer-topeer like relationship where each student has access to every other student's knowledge. And a rich wealth of information and interpersonal cooperation is open to learners as there is no obstruction occurring in the learning process. What's more, people within u-learning community can get access to education with high quality no matter where they are and what they are. Equal learning opportunity is enabled for all people, including those who are unable to join mainstream education. The true potential of u-learning is that, learners can not only learn life-long, but also learn life-wide. In other words, all people, as opposed to minority with much resource, are involved into educational scenarios. Learning belongs to everybody, and the equality will lead to an overall development of education in a country, or even in the world. Through the use of emerging wireless and mobile technologies, power space in college English autonomous learning field is improved and bettered by making computers everywhere and offering learners an equal and enjoyable learning experience.

\section{EPILOGUE}

As remarked above, this research is addressing a number of research topics pertinent to ubiquitous learning in view of Bourdieu's theory of practice, from preliminary analysis of college English autonomous learning field to practical suggestions for improvement and development of college English autonomous learning field. Within u-learning community, it's argued that physical space, informational space, social space and power space in college English autonomous learning field can be optimized and improved, and thereby overall improvement and development of college English autonomous learning field can be activated and achieved. Far-reaching benefits are anticipated for educational and learning situations with more advances in scientific technologies and educational reforms in future.

\section{ACKNOWLEDGMENTS}

This work is part of the project of On Establishing Generative Mechanism of EFL Autonomous Learning Behaviors and Strengthening Development of Learning Field in Ubiquitous Learning Space, the project of On Cultivating and Developing Liaoning Scientific Foreign Language Talents with View to Bourdieu' Theory, and the project of On Constructing Mechanism and Strategies for College English Autonomous Learning Abilities via Mobile Multimedia. This research was supported by the fund of Liaoning Provincial Federation Social Science Circles (Project No. 2017lslktyb-019), the fund of Liaoning Planning of Philosophy and Social Science (Project No. L16CYY001), and the fund of the Thirteenth Five-Year Plan of Education Sciences of Liaoning Province (Project No. JG16DB013).

\section{REFERENCES}

[1] Postill, J., Introduction: Theorising media and practice. In Bräuchler, B. and J. Postill (eds) Theorising Media and Practice. Oxford and New York: Berghahn, 2010.

[2] Ortner, S. B., Theory and Anthropology Since the Sixties. Comparative Studies in Society and History, 1984, 26(1).

[3] Postill, J., Introduction: Theorising media and practice. In Bräuchler, B. and J. Postill (eds) Theorising Media and Practice. Oxford and New York: Berghahn, 2010.

[4] Postill, J., Introduction: Theorising media and practice. In Bräuchler, B. and J. Postill (eds) Theorising Media and Practice. Oxford and New York: Berghahn, 2010.

[5] Scott,J. \& Marshall, G., Oxford Dictionary of Sociology. Oxford University Press, 2009.

[6] Eriksen, T.H. \& Nielsen. F.S., A History of Anthropology. London: Pluto Press, 2001.

[7] George S., Bourdieu's Disavowal of Lacan: Psychoanalytic Theory and the Concepts of "Habitus"and "Symbolic Capital". Blackwell Publishing Ltd., 2006.

[8] Bourdieu, P., Distinction: A Social Critique of the Judgment of Taste. London, Routledge, 1984.

[9] Beena G., Engendering Constructivist Learning in Tertiary Teaching. US-China Education Review A, 2012 (8). 